\title{
Protection of Cultivated Land Resources and Grain Supply Security in Main Grain-Producing Areas of China
}

\author{
Zhixin Zhang, Xiao Meng * and Ehsan Elahi
}

Citation: Zhang, Z.; Meng, X.; Elahi, E. Protection of Cultivated Land Resources and Grain Supply Security in Main Grain-Producing Areas of China. Sustainability 2022, 14, 2808. https://doi.org/10.3390/ su14052808

Academic Editor: Riccardo Testa

Received: 21 January 2022

Accepted: 22 February 2022

Published: 28 February 2022

Publisher's Note: MDPI stays neutral with regard to jurisdictional claims in published maps and institutional affiliations.

Copyright: () 2022 by the authors. Licensee MDPI, Basel, Switzerland. This article is an open access article distributed under the terms and conditions of the Creative Commons Attribution (CC BY) license (https:// creativecommons.org/licenses/by/ $4.0 /)$.
School of Economics, Shandong University of Technology (SDUT), Zibo 255022, China; beiji2002@126.com (Z.Z.); ehsanelahi@nuist.edu.cn (E.E.)

* Correspondence: mengxiao0320@163.com

\begin{abstract}
Land is a main factor in food production, and cultivated land resources provide opportunity for the national food security. This study empirically estimates the impact of farmland protection on the security of grain supply in major grain-producing areas of China. For this purpose, from 2010 to 2019, panel data was collected from 13 main grain-producing provinces of China. The results revealed that the protection of cultivated land resources in the main grain-producing areas with direct means, incentives, and technological progress, significantly and positively impacted the security of grain supply. Furthermore, a mismatch was found between resource conditions and their use for grain production in the Northern region, and the lack of protection of cultivated land resources in the Southern region, which leads to the insignificant positive promotion of grain supply security. The results of the study strongly suggest that central and national governments of China need to provide a proper policy for the protection of cultivated land resources with equal emphasis on quantity, quality, and sustainability to ensure food security.
\end{abstract}

Keywords: production; consumption; cultivated land resource; food security; mechanism analysis; China

\section{Introduction}

Although China focuses on massive agricultural production, food security is still a threat because of its growing population due to the three-child policy [1]. Particularly, China is in transformation from "raising output" to "raising production capacity" from four aspects: good farmland, good seeds, good machine, and good technology. From 1996 to 2009, about 3 million $\mathrm{hm}^{2}$ of high-quality cultivated land was converted into construction land in China [2]. By 2019, the area of advanced cultivated land accounted for less than one-third of the total cultivated land area $\left(421,333.33 \mathrm{~km}^{2}\right)$, and the area of low cultivated land accounted for $21.95 \%\left(296,000 \mathrm{~km}^{2}\right)$. Moreover, the soil fertility of this part of the cultivated land foundation was relatively poor (Data sources: Bulletin of national cultivated land quality grade in 2019). It is difficult to achieve fundamental improvement in a short period of time. China is focusing on the protection of cultivated land resources as a basic national policy. The main grain-producing areas in China have been contributing 75\% of the national grain output and $80 \%$ of commodity grain [3]. The grain-producing areas have an important role to ensure food security. Therefore, it is imperative to emphasize the protection of cultivated land resources and the security of grain supply in the main grain-producing areas of China.

The degradation of cultivated land quality leads to a decrease in food production [4-7]. The research on cultivated land protection can be divided into macro and micro levels. At the macro level, studies mainly have focused on the evolution and development direction of cultivated land protection policy in China. The cultivated land protection policy is the basic policy guarantee for grain production and has an important role in ensuring food security [8]. China's cultivated land protection policy gradually forms a "trinity" stage of cultivated land quantity, quality, and ecological sustainability from the simple 
quantitative protection stage [9]. Establishing a scientific and reasonable mechanism for the protection of cultivated land resources is an inevitable choice for China to realize food security. A strict cultivated land protection system has an irreplaceable fundamental role in guaranteeing Chinese people's food and security [10,11]. It is imperative to establish "food production capacity" indicators as the core of cultivated land protection policy through the perfect economic constraint mechanism control protection of farmland non-agricultural land. Building agricultural technology support, cultivating core grain production area construction and the development of ecological agriculture strategy implementation is urgent to protect the cultivated land resource and ensure food supply security $[2,12,13]$.

At the micro-level, previous studies have focused on the factors affecting farmers' cultivated land resource protection behaviour. Several factors such as age, gender, average annual income of cultivated land, per capital size of cultivated land, and degree of farmland fragmentation affect farmers' willingness to invest in the conservation of cultivated land. Similarly, studies have found that the land right confirmation and scale operation have a significant and positive impact on the behaviour of protecting cultivated land resources [14-16]. Existing studies have mostly focused on the impact of changes in the quantity and quality of cultivated land resources on food production and food supply security. However, the impact of macro and micro subjects' input of cultivated land resource protection on food security has not been considered in previous literature. Therefore, the current study focused on cultivated land resources protection and food security using data from major grain-producing areas of China. This article clarifies the mechanisms between the protection of cultivated land resources and food supply security. The article consists of five parts. The first part introduces the research background, research purpose, significance, and innovation of the article. The second part analyses the function and influence mechanisms between cultivated land resource protection and food supply security. The third part selects and introduces the research methods based on the research purpose, the influence mechanisms that explain the selection principles of the research variables, and makes a statistical description of the used data. The fourth part presents an analysis of the results, including the verification of three impact mechanisms, and a robust test and regional heterogeneity analysis. Similarly, the fifth part summarizes the research results and provides some suggestions.

\section{Influence Mechanisms}

\subsection{Direct Effects of Cultivated Land Resource Protection}

Grain yield is determined by grain yield per sown area [17]. The yield per unit area should be guaranteed by good quality of cultivated land, while sown area needs a certain amount of cultivated land resources [12]. The ecological sustainability of cultivated land also directly affects the sustainability of the food supply. Although large-scale and intensive management can ensure food supply security by increasing grain output per unit of cultivated land area to a certain extent, large-scale management is the scale of cultivated land, and intensive management is through the input of other productive factors and the marginal output of cultivated land. However, the contribution of cultivated land as a resource to food security mainly lies in the irreplaceability of cultivated land as a carrier of food production [10]. The protection of quantity, quality, and sustainability of cultivated land resources has a direct impact on food supply security.

\subsection{Incentive Effect of Cultivated Land Resource Protection}

While making decisions farmers conduct input-output analysis. A farmers' income is directly related to their enthusiasm for grain production [18]. Increasing farmers' income and enthusiasm for grain production is an important way to establish a long-term mechanism of food security [10]. Although farmers' input in cultivated land resource protection, such as the introduction of technology to protect cultivated land resources and the implementation of farming rotation, will increase the cost of grain planting, the government's input in cultivated land protection, such as cultivated land fertility protection subsidy and 
land fallow subsidy, will enable grain farmers to obtain transfer income and balance the increased cost of grain planting due to farmers' input in cultivated land resource protection. Protection of cultivated land can improve the level of cultivated land resource quantity, quality, and ecology, thereby enabling farmers to obtain more high-quality land. A large "quantity" can solve the high cost of grain production caused by the inability to promote large-scale operation, and overcome the dilemma of low income caused by the lack of cultivated land resources $[19,20]$. High "quality" can reduce the cost of grain production and increase the income of grain production by saving labour, fertilizer, pesticide and other production costs. We assume that the protection of cultivated land resources will ensure the security of the food supply by improving farmers' enthusiasm for growing grain.

\subsection{Effect of Technological Progress}

The protection of cultivated land resources in the main grain-producing areas impacted grain supply security through direct, incentive, and technological progress effects. The specific path is shown in Figure 1.

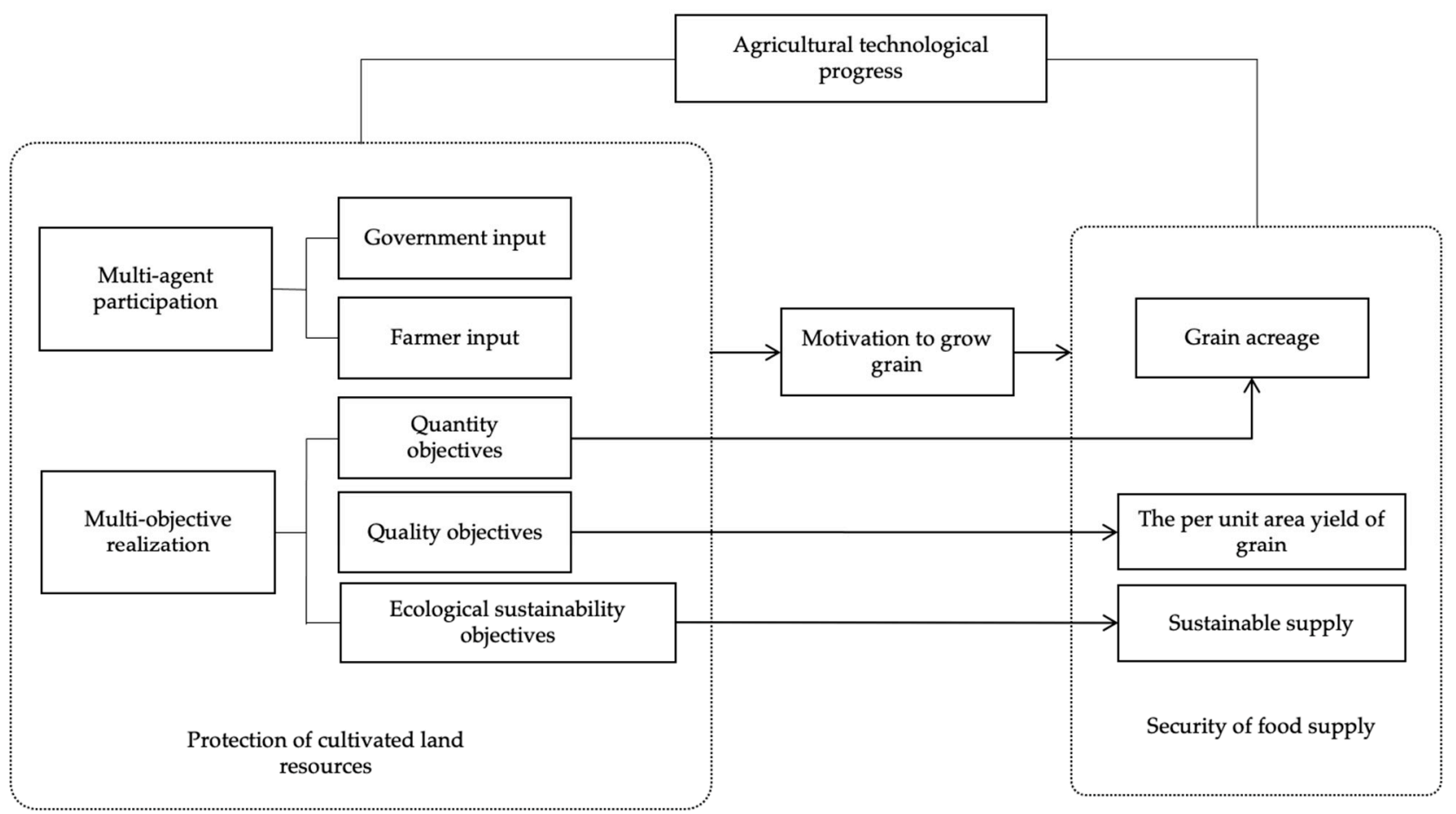

Figure 1. Mechanism of cultivated land resource protection and food supply security.

Advances in agricultural technology can increase food production by improving the quality of arable land. The input of agricultural technologies, such as biotechnology and pollution prevention technology can improve the quality of cultivated land and affect the total grain output by improving the yield per unit area, stability, and sustainability of grain production [21]. Moreover, agricultural techniques need to match the size of the land. The input of scientific and technological factors matching the scale of cultivated land can realize grain increase and ensure food supply security. The improvement and rational application of agricultural technology has a positive promotion effect of farmland protection and thus food supply security.

\section{Materials and Methods}

\subsection{Data Sources}

Based on the research purpose, the data from 13 major grain-producing provinces in China from 2010 to 2019 were collected, with a total of 130 samples. Particularly, the 
data were collected from the China Statistical Yearbook (2011-2020), China Rural Statistical Yearbook (2011-2020), China Environmental Statistical Yearbook (2011-2020), and the statistical yearbooks of the 13 major grain-producing provinces. Some missing data were supplemented by the average value method. As the selected panel data covers a short time span and the number of sections is larger than the number of time points $(n>\mathrm{T})$, the unit root test is no longer carried out.

\subsection{Variable Selection}

\subsubsection{Explained Variable}

Total grain output (gproduct) of the major grain-producing areas is selected to represent food supply security.

\subsubsection{Explanatory Variables}

The core explanatory variables of cultivated land resource protection are the result of multi-objective optimization. Cultivated land ownership belongs to the state. Land rights setting and institutional constraints play an important role. Since the 18th National Congress of the CPC, China has gradually formed a "trinity" pattern of cultivated land protection based on quantity control, quality management, and ecological management [22], which indicates that the protection of cultivated land resources includes quantity, quality, and ecological objectives. Referring to the multi-index comprehensive evaluation method adopted by Shuqin S., Cong M. and Guoming D. [23-25] in the study of cultivated land use, an index system of "multi-objective participation and multi-objective realization" was constructed. The multi-objective optimization problem of cultivated land resource protection was transformed into a single objective nonlinear problem by using entropy and a multiple linear objective function weighting method. The index system construction and the weight size and attribute of each index are given in Table 1.

Table 1. Cultivated land resource protection index system, and index weight.

\begin{tabular}{|c|c|c|c|c|c|}
\hline Target Layer & Criterion Layer & Index Layer & Index and Calculation Formula & Weight & Attribute \\
\hline \multirow{8}{*}{$\begin{array}{l}\text { Protection of } \\
\text { cultivated land } \\
\text { resources }\end{array}$} & \multirow{3}{*}{$\begin{array}{l}\text { Multi-agent } \\
\text { participation }\end{array}$} & $\begin{array}{l}\text { Government } \\
\text { involvement }\end{array}$ & $\begin{array}{l}\text { Expenditure on agriculture, forestry and water } \\
\text { conservancy/total fiscal expenditure }\end{array}$ & 0.1227 & + \\
\hline & & \multirow{2}{*}{$\begin{array}{c}\text { Farmers } \\
\text { involvement }\end{array}$} & Effective irrigated area/total cultivated area & 0.1221 & + \\
\hline & & & $\begin{array}{l}\text { Area covered by agricultural film/total area of } \\
\text { cultivated land }\end{array}$ & 0.1678 & + \\
\hline & \multirow{5}{*}{$\begin{array}{l}\text { Multi-objective } \\
\text { realization }\end{array}$} & $\begin{array}{l}\text { The cultivated } \\
\text { land quantity }\end{array}$ & $\begin{array}{c}\text { Total area of cultivated land/total area of } \\
\text { agricultural land }\end{array}$ & 0.1994 & + \\
\hline & & \multirow{2}{*}{$\begin{array}{l}\text { The cultivated } \\
\text { land quality }\end{array}$} & Disaster area/affected area & 0.1023 & - \\
\hline & & & Soil erosion control area & 0.1015 & + \\
\hline & & \multirow{2}{*}{$\begin{array}{c}\text { Ecological } \\
\text { sustainability }\end{array}$} & Fertilizer usage/total area of cultivated land & 0.0888 & - \\
\hline & & & Pesticide use/total area of cultivated land & 0.0953 & - \\
\hline
\end{tabular}

"+" and "-" symbols represent the positive and negative impacts of indicators on cultivated land resource protection, respectively.

Farmer participation in the protection of cultivated land resources is fully reflected in the process of cultivated land use. Based on existing studies, irrigation indices are taken as indicators of farmer participation in the protection of cultivated land resources $[23,25]$. Due to the natural properties of cultivated land, cultivated land quality is closely related to the ecological sustainability of cultivated land. Studies have shown that the decline of cultivated land quality is related to soil erosion, farmland pollution, and natural disasters [2]. Low-yield farmland with poor cultivated land quality is usually accompanied by natural disasters and serious soil erosion [23]. Therefore, the control area of soil erosion was selected as a positive index and the disaster rate as a negative index to represent the cultivated land 
quality protection target. Excessive use of chemical fertilizers and pesticides will bring soil compaction and organic pollution [26,27]. Some studies have pointed out that the average amount of fertilizer used in China is more than four times the world average, and about 1.8 million tons of pesticides are used every year [3]. Therefore, in this paper, the average use of fertilizer and pesticide was selected as a negative indicator to represent the goal of ecological sustainability for cultivated land resource protection [24,25].

\subsubsection{Control Variables}

Grain output is related to water resources, labour, production, and operation modes [28-31]. The water resource variable was represented by agricultural water consumption (Water). The labour force variable was expressed by the ratio of employment in one industry (jiuyebi), and the calculation formula was the employees in the primary industry/all employees. The Multiple Cropping Index (fzIndex) is the embodiment of crop production mode under natural light and heat conditions, and was calculated as the sown area of crops/the total area of cultivated land. Following Zhang Heng's study [32], the per capita land operation scale (guimo) was used to represent the operation mode.

\subsubsection{Mediation Variables and Threshold Variables}

In this article, the sum of household operating income and transfer income (JZ) is selected as the intermediary variable to represent the enthusiasm of farmers to grow grain, and further discuss the household operating income (jingying) and transfer income (zhuanyi) intermediary effect respectively. According to the mechanism analysis, agricultural technological progress is selected as the threshold variable, and the DEA-Malmquist index measurement method is adopted to quantify agricultural technological progress. Under constant returns to scale, this article takes the total agricultural output value as the output variable, and the number of employees of the first industry at the end of the year, the total amount of chemical fertilizer used, the effective irrigation rate, the sown area of crops, the total power of agricultural machinery as the input variables to calculate the total factor productivity (TFP) of agriculture by using DEAP2.0. The TFP is divided into a technical progress and technical efficiency index [33]. The technological progress index is selected to represent the threshold variable of agricultural technological progress (Tech).

\subsection{Analytical Framework}

\subsubsection{Baseline Regression Model}

According to the explained variables, core explanatory variables and control variables, the model is constructed as follows:

$$
Y_{i t}=\alpha+\beta X_{i t}+\sum_{k=1}^{4} \gamma_{k} Z_{k i t}+\varepsilon_{i t}
$$

where $Y_{i t}$ is the explained variable, $X_{i t}$ is the core explanatory variable, $Z_{k i t}$ is the control variable, $\varepsilon$ is the error term, which is assumed to be normally distributed with zero mean and constant variance $[34,35]$, and $k$ is the number of control variables. $X_{i t}$ represents the cultivated land quality protection, which is calculated by the entropy-multiple linear objective function weighting method. The entropy method is a mature objective weighting method, which has been widely used in solving practical problems. The specific calculation formula will not be described again. The formula of the multivariate linear objective function weighting method can be written as:

$$
G_{i}=\sum_{s=1}^{2} \sum_{j=1}^{m} X_{i j}^{\prime} \cdot w_{j}
$$

where $G_{i}$ is the final index value, $X_{i j}^{\prime}$ is the standardized value of the JTH index in region " $I$ ", $w_{j}$ is the weight of the JTH index, " $m$ " is the total number of index layers contained in 
the criterion layer, and " $s$ " is the number of criterion layers. This paper used panel data. First, a mixed OLS model regression was adopted. Then, a fixed effect model (FE) was used to solve the problem of the missing variables in the model set, and the heteroscedasticity standard error value was used to overcome the autocorrelation and heteroscedasticity problems. Finally, to overcome the possible endogeneity problem in the estimation model, the 2SLS model was adopted for regression, and the lag period of the core explanatory variable of cultivated land resource protection was selected as a tool variable to be added into Equation (1). According to the results of the time fixed effect joint test, it was concluded that the time fixed effect was not needed, and $\delta_{i}$ was an unobserved individual fixed effect. The Kleibergen-paap RK LM and the Cragg-Donald Wald F index were calculated for the unidentifiable test and weak test of instrumental variables, respectively (Equation (3)).

$$
Y_{i t}=\alpha+\beta X_{i t}+X_{i t-1}+\sum_{k=1}^{4} \gamma_{k} Z_{k i t}+\delta_{i}+\varepsilon_{i t}
$$

\subsubsection{Mediating Effect}

To explore whether the protection of cultivated land resources will affect the security of food supply through farmers' enthusiasm for growing grain, it is necessary to establish an intermediary utility model to test the significance of the intermediary effect of household operating income and transfer income as intermediary variables. The intermediary effect model can be constructed as [36]:

$$
\begin{gathered}
Y_{i t}=\alpha_{0}+c X_{i t}+\sum_{k=1}^{4} \gamma_{1 k} Z_{k i t}+\varepsilon_{1 i t} \\
M_{p i t}=\alpha_{1}+a X_{i t}+\sum_{k=1}^{4} \gamma_{2 k} Z_{k i t}+\varepsilon_{2 i t} \\
Y_{i t}=\alpha_{3}+c^{\prime} X_{i t}+b M_{i t}+\sum_{k=1}^{4} \gamma_{3 k} Z_{k i t}+\varepsilon_{3 i t}
\end{gathered}
$$

where $M_{\text {pit }}$ is the intermediary variable which is family operating income or transfer income; " $c$ " is the total effect of cultivated land resource protection on food supply security; " $a$ " is the effect of cultivated land resource protection on intermediary variables; " $c$ " is the direct effect of cultivated land resource protection on food supply security after controlling intermediary variables. " $b$ " is the effect of the intermediary variable on food supply security after controlling the protection of cultivated land resources. The product " $a b^{\text {" }}$ represents the mediating effect of household operating income or transfer income on the relationship between cultivated land protection and food supply security. Only when " $c$ ", " $a$ " and " $b$ " are significant, the multiplication of "ab" is significant, which proves that the intermediary effect exist. When the mediation effect exists, " $c$ " will be a partial mediation, otherwise, it will be a complete mediation.

\subsubsection{Panel Threshold Regression Model}

The feature of the panel threshold model is that it can automatically identify the jump point according to the given threshold variable. It also avoids the subjective setting error of grouping regression. To verify the nonlinear characteristics of the impact of cultivated land resource protection on food supply security, the panel threshold regression model proposed by Hansen [37] was adopted in this paper, and the threshold model was constructed as follows:

$$
Y_{i t}=\alpha_{4}+I\left(Q_{i t} \leq \eta\right) X_{i t \xi 1}+I\left(Q_{i t}>\eta\right) X_{i t \xi 2}+\sum_{k=1}^{4} \gamma_{k} Z_{k i t}+\varepsilon_{i t}
$$


where $Q_{i t}$ is the threshold variable agricultural technological progress; $\eta$ is the coefficient to be estimated; and $I(\cdot)$ is the indicator function. When the conditions in parentheses are satisfied, $I(\cdot)=1$, otherwise, it will be equal to 0 . The error term $\left(\varepsilon_{i}\right)$ is assumed to be normally distributed with a zero mean value and constant variance [38-40].

After obtaining the parameter estimates, it was necessary to test whether the threshold effect exists and determine the number of threshold values. The asymptotic distribution and $p$ value of $\mathrm{F}$ statistic were obtained by the bootstrap method. After the first threshold value was determined, we continued testing until all thresholds were found.

\section{Results and Discussion}

\subsection{Descriptive Statistics}

Descriptive statistics of each variable are shown in Table 2. The cultivated land resource protection index is the relative value calculated by using the comprehensive measurement method of multiple indicators. Its value potentially ranges from 0 to 1 , with the maximum value being 0.70 and the minimum value being 0.21 . So, the cultivated land resource protection of major grain-producing provinces varies greatly. The explained variable is the grain output of the main grain-producing provinces, with a large difference between maximum and minimum values, and the mean is closer to the minimum value, indicating that grain output is mostly concentrated in the middle and lower level. As for the control variables, the standard deviation of the cropping index and the proportion of people employed in primary industry was small, and the standard deviation of per capita land operation scale and agricultural water consumption was large, indicating that there was little variation in natural water and heat conditions and the proportion of people engaged in agriculture in the major grain-producing areas from 2010 to 2019, but there was a big difference in land concentration and agricultural water consumption. The Metavariables are the income of grain farmers engaged in grain planting activities and in different provinces they varied greatly in different years. The difference of family operation income was much greater than that of transfer income especially. The standard deviation of agricultural technological progress was small, indicating that the research and development, popularization and application of agricultural technology in different provinces were similar in different years.

Table 2. Summary of basic variables.

\begin{tabular}{|c|c|c|c|c|c|c|}
\hline Types of Variables & Variables & Definition of Variables & Maximum & Minimum & Mean & Standard Deviation \\
\hline Explained variable & gproduct & Food production & 7506.80 & 1753.90 & 3664.89 & 1362.30 \\
\hline \multirow[t]{2}{*}{ Core explanatory variable } & protect & Cultivated land resource protection index & 0.70 & 0.21 & 0.44 & 0.10 \\
\hline & jz & Household operating and transfer income & $15,005.20$ & 2723.84 & 7298.79 & 2756.91 \\
\hline \multirow[t]{2}{*}{ Metavariables } & jingying & Household operating income & $14,157.40$ & 2292.44 & 5578.15 & 2349.88 \\
\hline & zhuanyi & Transfer income & 4482.20 & 280.10 & 1720.64 & 1099.12 \\
\hline \multirow[t]{2}{*}{ Threshold variable } & tech & Agricultural technological progress & 1.34 & 0.98 & 1.09 & 0.06 \\
\hline & fzindex & Cropping index & 3.56 & 0.77 & 1.48 & 0.53 \\
\hline \multirow{3}{*}{ Control variables } & guimo & Per capita land operation scale & 24.81 & 4.55 & 8.40 & 4.56 \\
\hline & water & Agricultural water consumption & 316.40 & 73.84 & 162.41 & 63.57 \\
\hline & jiuyebi & Proportion of people employed in primary industry & 0.48 & 0.16 & 0.35 & 0.07 \\
\hline
\end{tabular}

\subsection{Impact of Cultivated Land Resource Protection on Security of Food Supply}

\subsubsection{Results of Baseline Regression}

According to the entropy-multiple linear objective function weighting method, the cultivated land protection index of the 13 provinces from 2010 to 2019 and its 10-year average value were calculated (Table 3). According to the mean value, Shandong, Inner Mongolia and Hebei ranked as the top three in cultivated land resource protection. While Jiangxi, Hunan, and Hubei ranked as the bottom three. 
Table 3. Protection of cultivated land resources in major grain-producing areas.

\begin{tabular}{|c|c|c|c|c|c|}
\hline Provinces & 2010 & 2014 & 2019 & Mean & Raking (According to the Mean Value) \\
\hline Liaoning & 0.29 & 0.38 & 0.39 & 0.36 & 10 \\
\hline Jilin & 0.56 & 0.41 & 0.44 & 0.46 & 6 \\
\hline Heilongjiang & 0.41 & 0.50 & 0.50 & 0.47 & 5 \\
\hline Shandong & 0.55 & 0.69 & 0.68 & 0.63 & 1 \\
\hline Henan & 0.35 & 0.48 & 0.46 & 0.42 & 9 \\
\hline Hebei & 0.42 & 0.56 & 0.51 & 0.49 & 3 \\
\hline Inner Mongolia & 0.49 & 0.51 & 0.56 & 0.53 & 2 \\
\hline Jiangxi & 0.33 & 0.37 & 0.33 & 0.34 & 12 \\
\hline Hubei & 0.21 & 0.30 & 0.32 & 0.30 & 13 \\
\hline Hunan & 0.35 & 0.37 & 0.38 & 0.35 & 11 \\
\hline Sichuan & 0.38 & 0.47 & 0.47 & 0.44 & 7 \\
\hline Jiangsu & 0.35 & 0.55 & 0.53 & 0.48 & 4 \\
\hline Anhui & 0.35 & 0.47 & 0.47 & 0.43 & 8 \\
\hline
\end{tabular}

To explore the impact of cultivated land protection on food supply security, we need to analyse the estimated results of the model (Table 4). The estimated results of Equations (1) and (3) are given in Table 4, while Equation (1) is the mixed OLS estimation, Equation (2) is the fixed effect estimation (FE), and Equation (3) is the 2SLS estimation with the addition of instrumental variables, as the cultivated land resource protection index was calculated by the comprehensive measure method of multiple indicators. We found the value of VIF (1.49) which is less than 10 . This implies that there is no multicollinearity problem in the data.

Table 4. Estimation results of cultivated land protection on food supply security.

\begin{tabular}{cccc}
\hline Variables & Model 1 & Model 2 & Model 3 \\
\hline \multirow{2}{*}{ lnprotect } & $0.7369^{* * *}$ & $0.1140^{* * *}$ & $0.2485^{* *}$ \\
& $(0.0876)$ & $(0.0471)$ & $(0.1129)$ \\
fzindex & 0.0009 & $-0.2184^{* * *}$ & $-0.1848^{* * *}$ \\
& $(0.0704)$ & $(0.0634)$ & $(0.0345)$ \\
lnwater & $0.2731^{* * *}$ & -0.0547 & -0.0848 \\
& $(0.1622)$ & $(0.1867)$ & $(0.1181)$ \\
guimo & $0.0112^{* *}$ & $0.0433^{* * *}$ & $0.0375^{* * *}$ \\
& $(0.0056)$ & $(0.0078)$ & $(0.0050)$ \\
jiuyebi & $0.8985^{* *}$ & $-0.7218^{* *}$ & $-0.3666^{*}$ \\
& $(0.3908)$ & $(0.2469)$ & $(0.1982)$ \\
Constant & $6.9941^{* * *}$ & $8.7269^{* * *}$ & - \\
$\mathrm{R}^{2}$ & $(0.3555)$ & $(0.9598)$ & 0.4800 \\
$n$ & 0.3995 & 0.5692 & 130 \\
\hline
\end{tabular}

*** and ${ }^{* * *}$ represents level of significance of parameters at $1 \%, 5 \%$ and $10 \%$, respectively. Kleibergen-Paap fairly rk LM = 10.285; Cragg-Donald Wald F = 28.140 (15\% Maximal IV size = 8.96), tool variables were selected reasonably.

Moreover, it was found that the cultivated land resource protection had a significant and positive correlation with food supply security, and the model effect was relatively robust (Table 4). Considering the optimal choice in overcoming endogeneity, the 2SLS model estimation results were selected for analysis. The core variables of cultivated land resource protection effect on the food supply security were under the $5 \%$ level of significance. It shows that through the active participation of macro and micro main level, the cultivated land resources quantity, quality, ecological sustainable comprehensive ascension can significantly increase the degree of grain food supply security, cultivated land resource protection. Particularly, every $1 \%$ point increase in cultivated land resource protection, grain output will increase by $24.85 \%$.. The significant negative correlation between the proportion of labour force in primary production and grain output may be due to the large amount of surplus labour force in rural areas affected by the return of labour force and aging population [41], and the problems of "overdensity" and "Involution" in the 
agricultural sector [42]. Therefore, the input of labour force alone can no longer guarantee grain output. The improvement of the quality of agricultural labour force, namely the cultivation of new professional farmers, is particularly important at this stage. Moderate scale agricultural operation can effectively alleviate the low-risk resistance ability of smallscale grain production and operation caused by natural disasters and market fluctuations, which is conducive to food supply security [30].

\subsubsection{Heterogeneity Analysis of the Main Grain Producing Areas of China}

In recent years, the economic gap between the North and South in China has increased rapidly [43]. The trend of the centre of grain production moving northward is also becoming more obvious, and a pattern of "grain transportation from the North to the South" has been formed in grain production. In this context, this paper takes the Qinling Mountains-Huaihe River as the traditional agricultural demarcation line, dividing the main grain producing areas into southern and northern regions, and explored the impact of the protection of cultivated land resources in them on the security of grain supply. The main grain-producing areas in northern China include Liaoning, Jilin, Heilongjiang, Shandong, Henan and Inner Mongolia. The main grain-producing areas in south China include Jiangsu, Hubei, Hunan, Sichuan, Anhui and Jiangxi provinces. The results are given in the Table 5.

Table 5. 2SLS estimation results of cultivated land protection on food supply security in Northern and Southern major grain-producing areas.

\begin{tabular}{ccc}
\hline Variables & Northern (7 Provinces) & Southern (6 Provinces) \\
\hline \multirow{2}{*}{ lnprotect } & $0.2095^{*}$ & 0.2983 \\
& $(0.1082)$ & $(0.3383)$ \\
fzindex & $-0.2758^{*}$ & -0.0249 \\
& $(0.1416)$ & $(0.0402)$ \\
lnwater & -0.1875 & -0.0091 \\
& $(0.1983)$ & $(0.1830)$ \\
guimo & $0.0463 * * *$ & 0.0037 \\
& $(0.0068)$ & $(0.0079)$ \\
jiuyebi & -0.3800 & $-1.0175^{* *}$ \\
R-sq & $(0.3188)$ & $(0.4883)$ \\
$n$ & 0.5563 & 0.3314 \\
$*_{*}^{* * *}$ and & 60 \\
\hline
\end{tabular}

The protection of cultivated land resources in the main grain producing areas in North China has a significant positive effect on security of grain supply. Compared with the main grain producing areas in the South, the negative impact of the multiple cropping index on grain yield in the North is more significant, mainly because there, especially in Northeast China and Inner Mongolia, high latitude, poor water, light and heat conditions, the arable land is mainly dry land. This is also an urgent problem of mismatch between resource conditions and grain production functions under the pattern of "grain transportation from North to South". In addition, the scale of the main grain producing areas in Northern China has a significant positive impact on grain yield. The main reason is that in Northern China they mainly grow corn and wheat, which have a simple production process and low technical difficulty, and the cultivated land type is mostly flat dry land. In the large-scale land use, turning, sowing and harvesting with large-scale agricultural machinery can obviously improve the efficiency of grain production and benefit the security of grain supply.

The protection of cultivated land resources in the main grain-producing areas in South China has no significant positive impact on security of grain supply. Combined with the calculation results of cultivated land resource protection (Figure 2), the protection level of cultivated land resources in the main producing areas of South China is always lower than that of those areas as a whole and of those in North China. The reason is that the 
quantity and quality of cultivated land protection policy are not guaranteed [44]. The quality of the cultivated land in the South is twice than that of the supplemented cultivated land in the Northeast plain and 3.54 times that of the supplemented cultivated land in the Eastern Inner Mongolia [45]. The protection of cultivated land resources in the main grain producing areas in the South is insufficient both in terms of the protection subject and the protection target. As a result, cultivated land protection has no significant positive impact on grain yield. Inadequate protection of cultivated land resources has not only led to a decline in grain yield per unit area, but also frustrate the enthusiasm of farmers to grow grain.

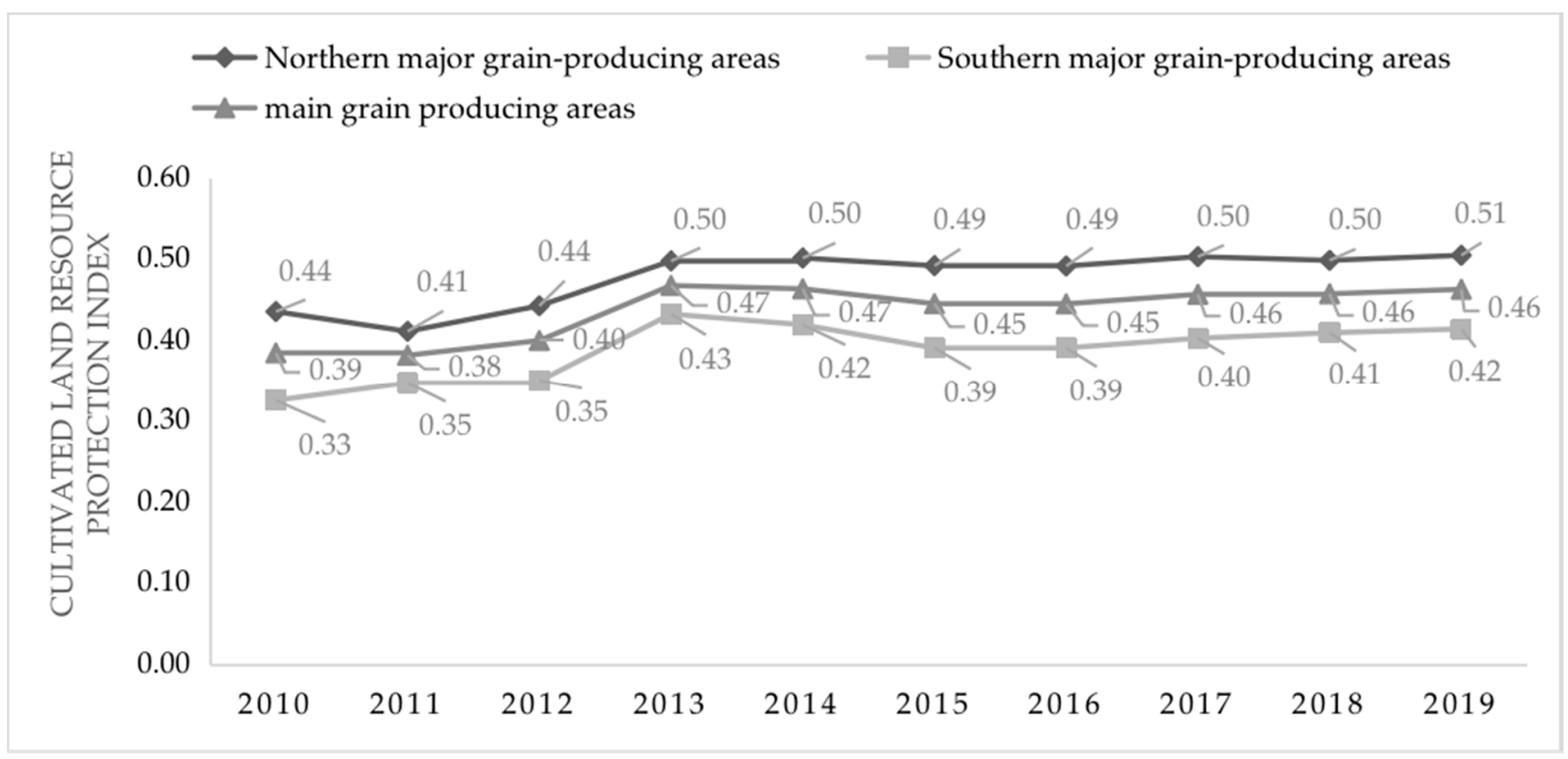

Figure 2. Cultivated land resource protection difference between main grain producing areas in North and South of China.

\subsubsection{Robustness Test}

In this article, grain yield (grproduct) was used as the explained variable to test the robustness of results. Compared with total grain production (gproduct), grain production (grproduct) is often used to measure ration security. Firstly, the logarithm of data was taken for grain yield, and then the FE and 2SLS models were used for regression. The results are given in Table 6:

Table 6. Robustness test.

\begin{tabular}{ccc}
\hline Variables & $\begin{array}{c}\text { Model 1 } \\
\text { FE }\end{array}$ & $\begin{array}{c}\text { Model 2 } \\
\text { 2SLS-Lngrproduct }\end{array}$ \\
\hline \multirow{2}{*}{ lnprotect } & $2.0276^{* * *}$ & $0.6944^{* *}$ \\
& $(0.4696)$ & $(0.3424)$ \\
fzindex & -0.0592 & -0.0422 \\
& $(0.0495)$ & $(0.0778)$ \\
lnwater & $0.9986^{* *}$ & $0.8997^{* *}$ \\
& $(0.3999)$ & $(0.3736)$ \\
guimo & -0.0046 & -0.0053 \\
& $(0.0098)$ & $(0.0141)$ \\
jiuyebi & -1.0444 & -0.6271 \\
& $(0.6494)$ & $(0.6161)$ \\
\hline
\end{tabular}


Table 6. Cont.

\begin{tabular}{ccc}
\hline Variables & $\begin{array}{c}\text { Model 1 } \\
\text { FE }\end{array}$ & $\begin{array}{c}\text { Model 2 } \\
\text { 2SLS-Lngrproduct }\end{array}$ \\
\hline \multirow{2}{*}{ Constant } & 2.7511 & - \\
$\mathrm{R}^{2}$ & $(1.8909)$ & 0.2399 \\
$n$ & 0.3225 & 130 \\
\hline ** and ${ }^{* * *}$ represents level of significance of parameters at 5\% and 10\%, respectively.
\end{tabular}

As shown in Table 6, after replacing grain yield with log grain yield, the 2SLS model regression results show that the impact of cultivated land resource protection on food supply security is still significant at the $5 \%$ level. This implies that cultivated land protection positively impacted on food supply security. It showed a strong robustness.

\subsection{Test of Mediating Effect}

The stepwise method was used to test the mediating effect of farmer enthusiasm for planting grain on the protection of cultivated land resources for the security of grain supply. The Sobel test was used to determine the rationality of the mediating effect and to calculate the proportion of the mediating effect. To avoid the reverse causality between income and grain yield, the income is treated with one stage lag. In the basic regression (Table 4), it was proven that the coefficient " $c$ " is significant and positive. Results in Table 7 showed that the impact of cultivated land resource protection on food supply security through farmer enthusiasm for growing grain. According to the estimation results of Equation (1) and Equation (2), the coefficients of " $\mathrm{c}$ ", " $\mathrm{c}$ "', A and B are all the same and significant at the $1 \%$ level. In the mechanism of farmland resource protection affecting food supply security, the mediation effect of grain planting initiative exists obviously. After applying the Sobel test, it was concluded that about $10.29 \%$ of the positive promotion effect of cultivated land resource protection on food supply security was realized through the intermediary effect of farmer enthusiasm for planting grain. Furthermore, this article explores the mediating effect of household operating income and transfer income respectively. The results of Equations (3) and (4) found the existence of the mediating effect of household operating income. It indicated that the production cost was reduced by farmland protection, which is more than the cost of farmer input in farmland protection. The results of Equations (5) and (6) do not pass the Sobel test. The mediating effect of transfer income was not significant. Where $C$ and A are significant, but B is not statistically significant, it indicates that the government's input of farmland resource protection, such as farmland fertility subsidy and fallow system subsidy, does effectively improve farmers' transfer income and farmers' enthusiasm for growing grain, but there is still the problem of inefficient use, resulting in insignificant grain increase effect.

Table 7. Test results of the mediation effect of farmers' enthusiasm for planting grain.

\begin{tabular}{ccccccc}
\hline Variables & $\begin{array}{c}\text { Model 1 } \\
\text { lnjz }\end{array}$ & $\begin{array}{c}\text { Model 2 } \\
\text { lngproduct }\end{array}$ & $\begin{array}{c}\text { Model 3 } \\
\text { lnjingying }\end{array}$ & $\begin{array}{c}\text { Model 4 } \\
\text { lngproduct }\end{array}$ & $\begin{array}{c}\text { Model 5 } \\
\text { lnzhuanyi }\end{array}$ & $\begin{array}{c}\text { Model 6 } \\
\text { lngproduct }\end{array}$ \\
\hline lnjz & - & $0.1621^{* *}$ & - & - & - \\
lnjingying & - & $(0.0577)$ & - & $0.1528^{* * *}$ & - \\
lnzhuanyi & - & - & $-0.0555)$ & - & - \\
lnprotect & $0.4806^{* *}$ & $0.6790^{* * *}$ & $0.4437^{* * *}$ & $0.6891^{* * *}$ & $0.5052^{*}$ & $0.7382 * *$ \\
fzindex & $(0.1552)$ & $(0.0919)$ & $(0.1672)$ & $(0.0933)$ & $(0.2892)$ & $(0.0919)$ \\
& -0.0278 & 0.0015 & $-0.1426^{* *}$ & 0.0188 & $0.3722^{* * *}$ & -0.0168 \\
$(0.1151)$ & $(0.0476)$ \\
\hline
\end{tabular}


Table 7. Cont.

\begin{tabular}{ccccccc}
\hline Variables & $\begin{array}{c}\text { Model 1 } \\
\text { lnjz }\end{array}$ & $\begin{array}{c}\text { Model 2 } \\
\text { lngproduct }\end{array}$ & $\begin{array}{c}\text { Model 3 } \\
\text { lnjingying }\end{array}$ & $\begin{array}{c}\text { Model 4 } \\
\text { lngproduct }\end{array}$ & $\begin{array}{c}\text { Model 5 } \\
\text { lnzhuanyi }\end{array}$ & $\begin{array}{c}\text { Model 6 } \\
\text { lngproduct }\end{array}$ \\
\hline lnwater & $-0.2067^{* *}$ & $0.2833^{* * *}$ & -0.1332 & $0.2701^{* * *}$ & $-0.5875^{* * *}$ & $0.2715^{* * *}$ \\
& $(0.0952)$ & $(0.0674)$ & $(0.0918)$ & $(0.0691)$ & $(0.1832)$ & $(0.0703)$ \\
guimo & $0.0395^{* * *}$ & 0.0064 & $0.0335^{* * *}$ & 0.0077 & $0.0638^{* * *}$ & $0.0104^{*}$ \\
& $(0.0077)$ & $(0.0059)$ & $(0.0080)$ & $(0.0060)$ & $(0.0147)$ & $(0.0060)$ \\
jiuyebi & $-1.4550^{* * *}$ & $1.2123^{* *}$ & $-1.1281^{* * *}$ & $1.1488^{* * *}$ & $-2.9835^{* * *}$ & $1.0869^{* * *}$ \\
R-sq & $(0.3840)$ & $(0.4148)$ & $(0.3430)$ & $(0.4191)$ & $(0.8865)$ & $(0.4096)$ \\
Sobel test & 0.3890 & 0.4320 & 0.4701 & 0.4279 & 0.2078 & 0.4150 \\
$n$ & Mediate Effect $=10.29 \%$ & Mediate Effect $=8.96 \%$ & 130 & 130 & 1 \\
\hline
\end{tabular}

$*{ }^{* *}$ and ${ }^{* * *}$ represents level of significance of parameters at $1 \%, 5 \%$, and $10 \%$, respectively.

\subsection{Threshold Effect}

According to the mechanism analysis, the impact of cultivated land resource protection on food supply security was related to the progress of agricultural technology. It was explored in the previous section that cultivated land resource protection had a significant and positive impact on food supply security. This part mainly explains that such a positive impact is not invariable and there is a nonlinear relationship. The agricultural technological progress index as measured by the DEA-Malmquist index was used as the threshold variable, and the number of thresholds and their significance were first determined, as shown in Table 8.

Table 8. Results of threshold effect.

\begin{tabular}{ccccccccc}
\hline \multirow{2}{*}{ Variable } & $\begin{array}{c}\text { Threshold } \\
\text { Category }\end{array}$ & $\begin{array}{c}\text { Threshold } \\
\text { Value }\end{array}$ & $\begin{array}{c}\text { Confidence } \\
\text { Interval }\end{array}$ & F-Value & $\boldsymbol{p}$-Value & $\begin{array}{c}\mathbf{1 \%} \text { Critical } \\
\text { Value }\end{array}$ & $\begin{array}{c}\mathbf{5 \%} \text { Critical } \\
\text { Value }\end{array}$ & $\begin{array}{c}\mathbf{1 0 \%} \text { Critical } \\
\text { Value }\end{array}$ \\
\hline \multirow{2}{*}{ lntech } & Single threshold & 0.0450 & $(0.0426,0.0459)$ & $26.43^{* * *}$ & 0.0020 & 11.0014 & 13.1895 & 18.7337 \\
& Double threshold & 0.1832 & $(0.1545,0.1848)$ & $15.97^{* * *}$ & 0.0060 & 9.3681 & 11.4150 & 14.5262 \\
\hline
\end{tabular}

*** represents level of significance of parameters at $1 \%$.

When agricultural technology progress is in different stages, the impact of cultivated land protection on food supply security is different, and the two present a non-linear relationship. The triple threshold does not pass the significance test, and finally the result of double threshold is obtained. The threshold model estimation results are shown in Table 9. When agricultural technological progress does not cross the first threshold, there is a negative correlation between the protection of cultivated land and the security of food supply, which may be due to the insufficient or mismatched input of agricultural technology and the insufficient utilization of cultivated land resources, leading to the decline of food yield. After crossing the first threshold, the correlation changes from negative to positive, but it is still not significant. Before crossing the second threshold, cultivated land resource protection and food supply security present a significant positive correlation at the level of $1 \%$. It was concluded that whether cultivated land resource protection can effectively promote food supply security is restricted by the progress of agricultural technology. The rational addition of agricultural technological progress makes the significant positive promoting effect of cultivated land resource protection on security of food supply security. Only when agricultural technological progress has reached a certain level, does it cross the second threshold value. 
Table 9. Results of threshold model estimation.

\begin{tabular}{cccc}
\hline Variables & Coefficient & Standard Error & $p$-Value \\
\hline $\begin{array}{c}\text { Lnprotect_0 } \\
(\text { lntech } \leq 0.0450)\end{array}$ & -0.0317 & 0.0514 & 0.539 \\
Lnprotect_1 & 0.0680 & 0.0450 & 0.134 \\
$(0.0450<$ lntech $\leq 0.1832)$ & & & \\
Lnprotect_2 & $0.1717^{* * *}$ & 0.0491 & 0.001 \\
$(0.1832<$ lntech $)$ & $-0.1817^{* * *}$ & 0.0293 & 0.000 \\
fzindex & -0.0386 & 0.0906 & 0.672 \\
lnwater & $0.0368^{* * *}$ & 0.0047 & 0.000 \\
guimo & $-0.5941^{* * *}$ & 0.2140 & 0.001 \\
jiuyebi & & & \\
\hline
\end{tabular}

*** represents level of significance of parameters at $1 \%$.

\section{Conclusions, Policy Implications and Future Research}

\subsection{Conclusion and Policy Implications}

The aim of this study was to evaluate the impact of farmland protection on security of grain supply in the major grain-producing areas of China. Various econometric tools were applied to approach the study objectives. The main conclusions of this study are given below.

Firstly, the cultivated land protection index of major grain-producing areas was calculated by constructing the cultivated land protection index system of "multi-subject participation and multi-objective realization", which proved that the protection of cultivated land in major grain-producing areas had a significant positive promotion effect on the security of grain supply. Under the grain production pattern of "transporting grain from the North to South", the protection of cultivated land resources in the main grain producing areas in the North can significantly improve grain yield, but there is a problem of mismatch between resource conditions and yield function. The cultivated land resource protection index in the main grain-producing areas in South of China is lower than in the North. Both the main body of cultivated land resource protection and the protection target of cultivated land resource are insufficient, which leads to the insignificant positive promotion effect of cultivated land resource protection on food supply security in the main grain-producing areas in South of China.

Secondly, through the intermediary effect, it was verified that the protection of cultivated land resources in the main grain-producing areas affects the security of grain supply by affecting the enthusiasm of grain farmers. Among them, farmer household operating income in main grain-producing areas plays a positive mediating role in the impact of farmland protection on grain supply security. The mediating effect of transfer income is not significant, and the governmental input of farmland protection has a problem of inefficiency.

Thirdly, the positive promoting effect of cultivated land protection on food supply security in major grain-producing areas is restricted by the progress of agricultural technology, presenting a double threshold nonlinear relationship, and only when agricultural technology crosses the second threshold, can the positive effect of cultivated land protection on food supply security be effectively released. Therefore, this paper believes that more strict protection of cultivated land resources should be implemented to ensure the security of food supply in China. Based on the findings, the study proposes following suggestions:

The provincial and central governments of China should have to provide incentive and restraint mechanisms for farmland protection. It is necessary to improve farmland infrastructure construction, including irrigation, plant protection, flood drainage and pollution control to reduce farmers' cost of grain production and to increase their enthusiasm for growing grain. The cultivated land resource protection goal should be formed with equal emphasis on quantity, quality, and sustainability. Moreover, the use of organic fertilizers should encourage to improve the quality of cultivated land. 


\subsection{Future Research}

This study gathered the data from 13 provinces of main grain producing areas of China to research the protection of cultivated land resources and food supply security. It was found that the protection of cultivated land resources had a significant positive impact on food supply security under the direct effect, incentive effect and technological progress effect. However, the positive role of cultivated land resources protection on food supply security needs to be further explored. Moreover, city or county level data should be considered to make a detailed, and comprehensive analysis.

Author Contributions: Conceptualization, Z.Z. and X.M.; methodology, X.M.; software, X.M.; validation, Z.Z, X.M. and E.E.; formal analysis, X.M.; investigation, X.M.; resources, X.M.; data curation, X.M.; writing — original draft preparation, X.M.; writing — review and editing, E.E.; visualization, X.M.; supervision, Z.Z. All authors have read and agreed to the published version of the manuscript.

Funding: This research received no external funding.

Institutional Review Board Statement: Not applicable.

Informed Consent Statement: Not applicable.

Data Availability Statement: The data are not publicly available due to restrictions of privacy.

Conflicts of Interest: The authors declare no conflict of interest.

\section{References}

1. Jiang, H.; Simonovic, S.P.; Yu, Z.; Wang, W. What are the main challenges facing the sustainable development of China's Yangtze economic belt in the future? An integrated view. Environ. Res. Commun. 2021, 3, 115005. [CrossRef]

2. Kong, X. China must Protect High-Quality Arable Land. Nature 2014, 506, 7. [CrossRef] [PubMed]

3. Wang, Y.J.; Fei, D.; Xin, L. The status and problems of grain production in the main grain production areas of China and policy suggestions. Res. Agric. Mod. 2018, 39, 37-47. [CrossRef]

4. Elahi, E.; Khalid, Z.; Weijun, C.; Zhang, H. The public policy of agricultural land allotment to agrarians and its impact on crop productivity in Punjab province of Pakistan. Land Use Policy 2019, 90, 104324. [CrossRef]

5. Elahi, E.; Weijun, C.; Zhang, H.; Abid, M. Use of artificial neural networks to rescue agrochemical-based health hazards: A resource optimisation method for cleaner crop production. J. Clean. Prod. 2019, 238, 117900. [CrossRef]

6. Elahi, E.; Weijun, C.; Zhang, H.; Nazeer, M. Agricultural intensification and damages to human health in relation to agrochemicals: Application of artificial intelligence. Land Use Policy 2019, 83, 461-474. [CrossRef]

7. Elahi, E.; Khalid, Z.; Tauni, M.Z.; Zhang, H.; Xing, L. Extreme weather events risk to crop-production and the adaptation of innovative management strategies to mitigate the risk: A retrospective survey of rural Punjab, Pakistan. Technovation 2021, 4, 102255. [CrossRef]

8. Xiao, L.V.; Huang, X.; Chen, Z.; Tang, J.; Zhao, Y. Evaluation on the Grain Production Performance of the Cultivated Land Protection Policy in China. Resour. Sci. 2010, 32, 2343-2348.

9. Xiangbin, K. The goal framework and path of transformation of Cultivated land protection in China under the background of recuperation system. J. Soc. Sci. Hunan Norm. Univ. 2021, 50,1-12.

10. Ying, N. Contribution of cultivated land to food security in China. Economist 2015, 1, 83-93.

11. Yalan, L. Research on cultivated land resource protection strategy in China from the perspective of food security. Ecol. Econ. 2009, 2,109-111, 154 .

12. Zhong, S.; Li, K. Countermeasure for Farm land Protection Based on Food Security. China Soft Sci. 2009, 9, 1-8.

13. Li, X.; Jiang, D.; Bian, Z. The Surplus and Deficit Measurement of the Cultivated Land in China in the View of Food Security. Resour. Sci. 2014, 36, 2057-2065.

14. Meiqiu, C.; Lini, F.; Bingjuan, Z.; Aizhen, D. Empirical analysis of farmers' willingness to invest in cultivated land conservation. China Rural Surv. 2008, 5, 23-29.

15. Long, Q.; Yonghui, F.; Wenrong, Q. Farmland Certification, Adjustment Experience and Farmer's Land Quality Protection Behavior. J. Agrotech. Econ. 2021, 1, 61-76.

16. Chao, Z.; Kaiyu, L.; Chongshang, Z. Characteristics of production and management behavior and cultivated land quality of grain scale farmers. Jiangsu Agric. Sci. 2021, 49, 220-225.

17. Elahi, E.; Abid, M.; Zhang, L.; Ul Haq, S.; Sahito, J.G.M. Agricultural advisory and financial services; farm level access, outreach and impact in a mixed cropping district of Punjab, Pakistan. Land Use policy 2018, 71, 249-260. [CrossRef]

18. Na, W.; Ying, G.; Yonghong, W. Analysis on influencing factors of grain production and farmer income in main grain producing areas in China. Qinghai Soc. Sci. 2015, 2, 49-56. 
19. Xiang, L.; Jing, L.; Lu, Z. Arable land pressure and Urbanization in China: An empirical study based on geographical differences. Chin. J. Popul. Sci. 2015, 4, 47-59, 127.

20. Kong, X. Food security: The role of cultivated land should not be ignored-A response to MAO Yushi's statement that "the red line of 1.8 billion mu has nothing to do with food security". China Land 2011, 6, 57-60.

21. Garnett, T.; Appleby, M.C.; Balmford, A.; Bateman, I.J.; Benton, T.G.; Bloomer, P.; Burlingame, B.; Dawkins, M.; Dolan, L.; Fraser, D.; et al. Sustainable intensification in agriculture: Premise and policies. Science 2013, 341, 33-34. [CrossRef] [PubMed]

22. Leng, Z.; Fu, C. Impact of unbalanced urbanization development on food security. Economist 2014, 11, 58-65.

23. Shi, S.; Chen, Y.; Yao, Y.; Li, Z.; He, Y. Impact Assessment of Cultivated Land Change upon Grain Productive Capacity in Northeast China. Acta Geogr. Sin. 2008, 6, 574-586.

24. Cong, M.; Jian, L. Evaluation of cultivated land use efficiency based on entropy TOPSIS model and identification of its obstacle factors: A case study of three regions in the east, middle and west of China. J. China Agric. Univ. Soc. Sci. 2021, 26, 196-210.

25. Du, G.; Guo, K.; Yu, F. Suggestions on the transition and regulation of farmland utilization function in Heilongiang Province. Res. Agric. Mod. 2021, 42, 589-599.

26. Gao, Y.; Zhang, Z.; Wei, S.; Wang, Z. Impact of urbanization on food security: Evidence from provincial panel data in China. Resour. Sci. 2019, 41, 1462-1474. [CrossRef]

27. Chen, $X$. What pressure is China's agriculture facing? China's Constr. Old Revolut. Basic Area 2015, $2,14$.

28. Wang, G.; Qian, L. Grain Security Strategy in the 70 Years Since the Founding of New China: Evolution Path and Internal Logic. Chin. Rural Econ. 2019, 9, 15-29.

29. Zeying, L.; Yijun, H. Difficulties and Solutions of Ensuring Food Supply Under the Rural Revitalization Strategy. J. Northwest AF Univ. Soc. Sci. Ed. 2020, 20, 10-18.

30. Yiguo, X.; Shunsheng, G. Operation of Appropriate Scale in Agriculture and New-style Professional Farmer under the Angle of Food Safety: Coupling Mechanism, International Experience \& Revelation. Issues Agric. Econ. 2015, 36, 56-64, 111.

31. Zhou, Z.; Zhen, M. Influential factors decomposition for China's grain yield based on logarithmic mean Divisia index method. Trans. Chin. Soc. Agric. Eng. 2015, 31, 1-6.

32. Zhang, H.; Guo, X. Agricultural producer services, agricultural technology progress, and farmers' income growth: Analysis based on the mediation effect and the panel threshold model. Res. Agric. Mod. 2021, 41, 1-12.

33. Zhang, Z.; Lin, L.; Huang, H. Effects of Agricultural Technology Progress on Farmers Incomes: Evidence from 14 Agricultural Provinces in China. Forum Sci. Technol. China 2020, 8, 138-147.

34. Elahi, E.; Abid, M.; Zhang, H.; Cui, W.; Hasson, S.U. Domestic water buffaloes: Access to surface water, disease prevalence and associated economic losses. Prev. Vet. Med. 2018, 154, 102-112. [CrossRef] [PubMed]

35. Elahi, E.; Zhang, L.; Abid, M.; Javed, M.T.; Xin, H. Direct and indirect effects of wastewater use and herd environment on the occurrence of animal diseases and animal health in Pakistan. Environ. Sci. Pollut. Res. Int. 2017, 24, 6819-6832. [CrossRef]

36. Baron, M.; Kenny, A. The moderator-mediator variable distinction in social psychological research: Conceptual, strategic, and statistical considerations. J. Personal. Soc. Psychol. 1986, 51, 1173-1182. [CrossRef]

37. Hansen, E. Threshold effects in non-dynamic panels: Estimation, testing and inference. J. Econom. 1999, 93, 345-368. [CrossRef]

38. Elahi, E.; Khalid, Z.; Zhang, Z. Understanding farmers' intention and willingness to install renewable energy technology: A solution to reduce the environmental emissions of agriculture. Appl. Energy 2022, 309, 118459. [CrossRef]

39. Elahi, E.; Zhang, Z.; Khalid, Z.; Xu, H. Application of an artificial neural network to optimise energy inputs: An energy-and cost-saving strategy for commercial poultry farms. Energy 2022, 244, 123169. [CrossRef]

40. Elahi, E.; Zhang, H.; Xing, L.; Khalid, Z.; Xu, H. Understanding cognitive and socio-psychological factors determining farmers' intentions to use improved grassland: Implications of land use policy for sustainable pasture production. Land Use Policy 2021, 102, 105250. [CrossRef]

41. Yanan, W.; Jing, X.; Funing, Z. Return of Labor Force, Aging and "Lewis Turning Point". Issues Agric. Econ. 2020, 12, 4-16.

42. Fan, X. Analysis on Agricultural Involution. Econ. Probl. 2017, 8, 73-77.

43. Hua, L.; Yanlin, D. Exploration on the high quality development level of Chinese economy and the sources of its differences: Based on the perspective of inclusive green total factor productivity. J. Financ. Econ. 2021, 47, 4-18.

44. Jiang, M.; Li, X.; Xin, L.; Tan, M. The impact of paddy rice multiple cropping index changes in Southern China on national grain production capacity and its policy implications. Acta Geogr. Sin. 2019, 74, 32-43.

45. Li, Y.; Li, X.; Tan, M.; Xue, W.; Xin, L. The impact of cultivated land spatial shift on food crop production in China, 1990-2010. Land Degrad. Dev. 2018, 29, 1652-1659. [CrossRef] 